\title{
Contact Investigation of Children Exposed to Tuberculosis in South East Asia: A Systematic Review
}

\author{
Rina Triasih, ${ }^{1,2,3}$ Merrin Rutherford, ${ }^{4}$ Trisasi Lestari, ${ }^{5}$ Adi Utarini, ${ }^{5}$ \\ Colin F. Robertson, ${ }^{3}$ and Stephen M. Graham ${ }^{2,6}$ \\ ${ }^{1}$ Department of Paediatrics, Faculty of Medicine, Gadjah Mada University, Yogyakarta 55284, Indonesia \\ ${ }^{2}$ Centre for International Child Health, Department of Paediatrics and Murdoch Childrens Research Institute, \\ Royal Children's Hospital, University of Melbourne, Melbourne, VIC 3052, Australia \\ ${ }^{3}$ Department of Respiratory Medicine, Royal Children's Hospital, Melbourne, VIC 3052, Australia \\ ${ }^{4}$ Center for International Health, University of Otago, Dunedin 9050, New Zealand \\ ${ }^{5}$ Department of Public Health, Faculty of Medicine, Gadjah Mada University, Yogyakarta 55281, Indonesia \\ ${ }^{6}$ Child Lung Health, International Union Against Tuberculosis and Lung Disease, 75006 Paris, France
}

Correspondence should be addressed to Rina Triasih, rina_triasih@yahoo.com

Received 17 August 2011; Revised 30 September 2011; Accepted 2 October 2011

Academic Editor: Abu Syed Golam Faruque

Copyright ( 2012 Rina Triasih et al. This is an open access article distributed under the Creative Commons Attribution License, which permits unrestricted use, distribution, and reproduction in any medium, provided the original work is properly cited.

\begin{abstract}
Background. Screening of children who are household contacts of tuberculosis (TB) cases is universally recommended but rarely implemented in TB endemic setting. This paper aims to summarise published data of the prevalence of TB infection and disease among child contacts in South East Asia. Methods. Search strategies were developed to identify all published studies from South East Asia of household contact investigation that included children (0-15 years). Results. Eleven studies were eligible for review. There was heterogeneity across the studies. TB infection was common among child contacts under 15 years of age (24.4-69.2\%) and was higher than the prevalence of TB disease, which varied from 3.3\% to 5.5\%. Conclusion. TB infection is common among children that are household contacts of TB cases in South East Asia. Novel approaches to child contact screening and management that improve implementation in South East Asia need to be further evaluated.
\end{abstract}

\section{Introduction}

South East Asia is home to one-third of the global burden of tuberculosis (TB), with an estimated 5 million prevalent cases and an annual incidence of 3 million TB cases. Five of the 11 countries in the region are among the 22 highburden countries, with India accounting for over $20 \%$ of the global burden of TB disease $[1,2]$. Using the current strategy of passive case finding, the case detection rate in the region has improved from around $40 \%$ in 2002 to $65 \%$ in 2008 . However, it has stagnated since 2006 and remains below the target of more than 70\% [3].

A lower than expected case detection rate indicates that $\mathrm{TB}$ cases in the community are not being adequately identified and treated, which means ongoing transmission of TB infection [4]. The risk of transmission increases with the closeness of contact, overcrowded living conditions, and the degree of infectiousness of a TB case as determined by the positivity of sputum smear microscopy of acid-fast bacilli (AFB) and degree of lung field involvement in the chest $\mathrm{X}$ ray (CXR) $[5,6]$. Close contacts to a TB case such as those living in the same household are at higher risk of infection than casual contacts. Among those that are infected, young children ( $<5$ years) or those with immunodeficiency (e.g., HIV infected) are at increased risk of developing TB disease, usually within two years following infection [7]. Therefore, the World Health Organization (WHO), the International Union against Tuberculosis and Lung Diseases (IUATLD) and the National TB Control Programs (NTPs) recommend screening of all children who are household contacts of sputum smear-positive TB case [8].

Screening and management of child contacts has great potential to reduce TB-related morbidity and mortality in children $[4,9]$. It may prevent progression from infection 
to disease by early initiation of preventive therapy. It also can identify contacts of any age with suspected TB disease at an earlier stage than they otherwise may have presented to health care services. It, therefore, has the potential to increase case finding and reduce transmission [10]. Finally, though the contribution of young children to transmission may be small, they may form a pool of infection from which future adult cases arise $[11,12]$.

Despite the benefits, contact investigation for child contacts is rarely implemented and reported in resourcelimited TB endemic settings, such as in the South East Asia. This paper aims to collate published data reporting the prevalence of TB infection and TB disease among child household contacts of TB in the South East Asia region.

\section{Methods}

2.1. Search Strategies. The search strategies were developed using a combination of subject headings and keywords, including "tuberculosis," "Mycobacterium tuberculosis," "contact tracing," "contact investigation," "contact screening," "household contact," "close contact," and "family contact." The primary studies were searched electronically using databases PubMed, Embase, and Web of Science. Manual searching of the reference lists of the primary studies was performed to identify other eligible studies.

Published studies were included if they included children and adolescents (0-15 years), reported the yield of household contact investigation in children or provided data to calculate the prevalence of TB infection or TB disease in children, and were conducted in countries in the South East Asia region. Cross-sectional, prospective, and retrospective studies were included. The search was limited to published studies reported in English.

2.2. Data Extraction. Data were extracted using a modified Cochrane data extraction form. The data extracted included the following information: study site, design, description of index cases, description of household contacts, definition of household contacts, investigations performed (tuberculin skin test (TST), CXR, sputum smear microscopy of AFB, and culture of Mycobacterium tuberculosis), outcomes among child contacts (healthy, TB infection, or TB disease), and the criteria used to determine the outcomes.

\section{Results}

The literature search revealed 1087 references of which 11 studies satisfied the inclusion criteria. There have been systematic reviews and a meta-analysis on contact investigation of TB, but none specifically assessed the yield from household contact investigation among children in the South East Asia region $[13,14]$.

3.1. Study Characteristics. Eleven eligible studies were conducted in seven countries in South East Asia: India (four studies) [15-18], Thailand (two studies) $[19,20]$, and one study each from Cambodia [21], Indonesia [22], Lao People's
Democratic Republic [23], Pakistan [24], and Philippines [25]. Not all of the studies evaluated the prevalence of both TB infection and TB disease: five studies provided data on both; five studies evaluated the prevalence of TB infection only and one study of TB disease only. There was heterogeneity among studies with regards to epidemiology background, study design, the characteristics of the index case and child contact, and the criteria used for determining TB infection and TB disease (Table 1).

Most studies were cross-sectional in design, and only one study conducted in India in 1960s performed a prospective followup for a period of 5 years [18]. The index case in most studies was a case of sputum smear-positive pulmonary TB (PTB). The study from Indonesia evaluated household contacts of an index case with sputum smear-negative PTB [22], and two studies in India included sputum smearpositive and smear-negative cases with abnormal CXR [15, 16]. With regard to child contacts, three studies involved children under five only $[15,21,22]$, the others included older children up to 14-18 years of age [16-20, 23-25].

There was no uniform definition of a household contact across the studies, but the most common definition was a child living in the same house as the index case. Four studies specified a period of at least 3 months of living at the same house to define household contacts [19, 22, 24, 25]. A study in India defined close contact as living, cooking, and eating in the same house as the index case for the period of three months immediately preceding the start of treatment for the index case [18].

All studies which provided data on TB infection defined it as a positive TST, evaluated 48-72 after administration of tuberculin solution. However, there was a variation in the definition for a positive TST. Four studies used a cutoff of $10 \mathrm{~mm}$, whereas The Philippines study used $5 \mathrm{~mm}$ and the Thailand study used $15 \mathrm{~mm}$. Similarly, the criteria used to diagnose TB disease were different across studies. The study from Indonesia used the local scoring system [22], whereas most other studies used clinical and radiological features.

\subsection{The Yield of $T B$ Infection and $T B$ Disease among Child} Contacts. The number of child contacts investigated in the studies ranged from 61 to 790 children of 50 to 342 index cases. In general, the prevalence of TB infection among child contacts under 15 years of age was higher (24.4-69.2\%) than that of active TB disease $(3.3-5.5 \%)$. TB disease was more commonly found among children aged less than 5 years, whereas TB infection was more common in older children (Table 2).

The results of household contact investigation across the eligible studies cannot be compared directly due to the heterogeneity, particularly in outcome definitions (TB disease or TB infection). Figure 1 presents the yield of TB infection from studies which used a cutoff of $10 \mathrm{~mm}$ of TST result for TB infection among sputum smear-positive index cases. It is shown that $\mathrm{TB}$ infection is more common in children aged more than 5 years. The prevalence of infection in all children ranged from $24.4 \%$ to $38.8 \%$, with a weighted yield of $31 \%$. 
TABle 1: Characteristic of the studies.

\begin{tabular}{|c|c|c|c|c|c|c|c|c|}
\hline Author & Country & $\begin{array}{l}\text { Year of } \\
\text { study }\end{array}$ & $\begin{array}{l}\text { Epidemiology } \\
\text { features }\end{array}$ & $\begin{array}{c}\text { Characteristics } \\
\text { of index case }\end{array}$ & $\begin{array}{c}\text { Characteristics } \\
\text { of contact }\end{array}$ & $\begin{array}{c}\text { Criteria of } \\
\text { TST }(+)\end{array}$ & $\begin{array}{l}\text { TB disease } \\
\text { diagnosis }\end{array}$ & $\begin{array}{l}\text { Method of } \\
\text { sputum } \\
\text { collection }\end{array}$ \\
\hline $\begin{array}{l}\text { Andrews et al. } \\
{[18]}\end{array}$ & India & $1960 \mathrm{~s}$ & NA & SS $(+)$ & $\begin{array}{l}\text { Adults and } \\
\text { children }\end{array}$ & $\begin{array}{l}\text { At } 48-72 \text { hrs, } \\
\text { not specified }\end{array}$ & $\begin{array}{c}\text { Clinical, } \\
\text { CXR, and/or } \\
\text { microbiology }\end{array}$ & Laryngeal swab \\
\hline $\begin{array}{l}\text { Narain et al. } \\
{[16]}\end{array}$ & India & $1960 / 1961$ & NA & $\begin{array}{l}\text { SS }(+) \text { or } \\
\text { CXR }(+)\end{array}$ & $\begin{array}{l}\text { Adults and } \\
\text { children }\end{array}$ & $\begin{array}{c}\text { Not } \\
\text { explained }\end{array}$ & NA & $\begin{array}{l}\text { No detail } \\
\text { information } \\
\text { for children }\end{array}$ \\
\hline $\begin{array}{l}\text { Kumar et al. } \\
{[17]}\end{array}$ & India & $1982 / 1983$ & NA & SS $(+)$ & $\begin{array}{l}\text { Adults and } \\
\text { children }\end{array}$ & $\begin{array}{c}\text { Not } \\
\text { performed }\end{array}$ & $\begin{array}{c}\text { Clinical, } \\
\text { CXR, and/or } \\
\text { microbiology }\end{array}$ & Spot collection \\
\hline Singh et al. [15] & India & NA & NA & $\begin{array}{l}\text { SS }(+) \text { and } \\
\text { SS }(-) \text { but } \\
\text { CXR }(+)\end{array}$ & $<5$ yo & $\begin{array}{l}10 \mathrm{~mm} \text { at } \\
72 \mathrm{hrs}\end{array}$ & $\begin{array}{l}\text { Clinical and } \\
\text { CXR }\end{array}$ & Gastric lavage \\
\hline Rathi et al. [24] & Pakistan & 1999 & NA & $\begin{array}{l}>15 \text { yo } \\
\text { SS }(+)\end{array}$ & $\begin{array}{l}\text { Adults and } \\
\text { children }\end{array}$ & $\begin{array}{l}\text { At } 72 \text { hrs: } \\
10 \mathrm{~mm} \text { if } \\
\text { BCG }(-) \\
15 \mathrm{~mm} \text { if } \\
\text { BCG }(+)\end{array}$ & NA & Not performed \\
\hline $\begin{array}{l}\text { Salazar-Vergara } \\
\text { et al. [25] }\end{array}$ & Philippines & 2001 & NA & SS $(+)$ & $0-15$ yo & $\begin{array}{l}5 \mathrm{~mm} \text { at } \\
48-72 \mathrm{hrs}\end{array}$ & $\begin{array}{c}\text { Clinical, } \\
\text { CXR, and/or } \\
\text { microbiology }\end{array}$ & $\begin{array}{l}\text { Gastric aspirate } \\
\text { if CXR } \\
\text { suggestive of TB }\end{array}$ \\
\hline $\begin{array}{l}\text { Tornee et al. } \\
{[19]}\end{array}$ & Thailand & $2002 / 2003$ & NA & $\begin{array}{l}>15 \text { yo } \\
\text { SS }(+)\end{array}$ & $1-14$ yo & $\begin{array}{c}15 \mathrm{~mm} \text { at } \\
48 \mathrm{hrs}\end{array}$ & NA & Not performed \\
\hline $\begin{array}{l}\text { Tornee et al. } \\
{[20]}\end{array}$ & Thailand & 2003 & NA & $\begin{array}{l}>15 \text { yo } \\
\text { SS }(+)\end{array}$ & $<15$ yo & NA & NA & Not performed \\
\hline $\begin{array}{l}\text { Iskandar et al. } \\
{[22]}\end{array}$ & Indonesia & 2006 & $\begin{array}{l}\text { incidence: } \\
\text { 245/100000 } \\
\text { prevalence: } \\
675 / 100000\end{array}$ & $\begin{array}{l}\text { Adult, } \\
\text { SS (-) }\end{array}$ & $\begin{array}{c}4-60 \text { months } \\
\text { of age }\end{array}$ & $\begin{array}{l}10 \mathrm{~mm} \text { at } \\
72 \mathrm{hrs}\end{array}$ & $\begin{array}{l}\text { Indonesia } \\
\text { scoring } \\
\text { system }\end{array}$ & Not performed \\
\hline $\begin{array}{l}\text { Nguyen et al. } \\
{[23]}\end{array}$ & Lao & 2006 & $\begin{array}{l}\text { incidence: } \\
\text { 151/100000 } \\
\text { prevalence: } \\
289 / 100000\end{array}$ & $\begin{array}{l}>15 \text { y.o. } \\
\text { SS }(+)\end{array}$ & $\begin{array}{l}\text { Adults and } \\
\text { children }\end{array}$ & $\begin{array}{l}10 \mathrm{~mm} \text { at } \\
48-72 \mathrm{hrs}\end{array}$ & NA & Not performed \\
\hline Okada et al. [21] & Cambodia & 2005 & NA & $\begin{array}{c}\text { Adult, SS (+) } \\
\text { and SS (-) }\end{array}$ & $<5$ yo & $\begin{array}{c}10 \mathrm{~mm} \text { at } \\
72 \mathrm{hrs}\end{array}$ & $\begin{array}{c}\text { Clinical, TST, } \\
\text { and CXR }\end{array}$ & Not performed \\
\hline
\end{tabular}

NA: not available; SS (+): sputum smear positive; SS (-): sputum smear-negative; y.o.: years old; hrs: hours.

TABLE 2: The yields of household contact investigation among child contacts.

\begin{tabular}{|c|c|c|c|c|c|c|c|c|c|}
\hline \multirow{2}{*}{ Author } & \multirow{2}{*}{ Country } & \multirow{2}{*}{$\begin{array}{l}\text { Number of } \\
\text { source case }\end{array}$} & \multirow{2}{*}{$\begin{array}{l}\text { Number of } \\
\text { child contacts }\end{array}$} & \multicolumn{3}{|c|}{ Yield (\%) for TB infection } & \multicolumn{3}{|c|}{ Yield (\%) for TB disease } \\
\hline & & & & $<5$ yo & $5-15$ yo & $<15$ yo & $<5$ yo & $5-15$ yo & $<15$ yo \\
\hline Andrews et al. [18] & India & 191 & 398 & 16.2 & 53.6 & 38.8 & 9.2 & 3 & 5.5 \\
\hline Narain et al. [16] & India & 75 & 790 & 5.5 & 36.5 & 24.4 & NR & NR & NR \\
\hline Kumar et al. [17] & India & 50 & 142 & NR & NR & NR & 3.2 & NR & NR \\
\hline Singh et al. [15] & India & 200 & 281 & 33.8 & NR & NR & 3.2 & NR & NR \\
\hline Rathi et al. [24] & Pakistan & 77 & 151 & 7.8 & 21.8 & 29.6 & NR & NR & NR \\
\hline $\begin{array}{l}\text { Salazar-Vergara et al. } \\
{[25]}\end{array}$ & Philippines & 62 & 153 & 51.2 & 76.9 & 69.2 & NR & NR & 3.3 \\
\hline Tornee et al. [19] & Thailand & 325 & 480 & NR & NR & 47.8 & NR & NR & NR \\
\hline Tornee et al. [20] & Thailand & 342 & 500 & NR & NR & 47.1 & NR & NR & NR \\
\hline Iskandar et al. [22] & Indonesia & 54 & 61 & 10 & NR & NR & 16.4 & NR & NR \\
\hline Nguyen et al. [23] & Lao & 72 & 148 & 26 & 35.7 & 31.1 & NR & NR & NR \\
\hline Okada et al. [21] & Cambodia & 164 & 217 & 24 & NR & NR & 8.7 & NR & NR \\
\hline
\end{tabular}

NR: not reported. 


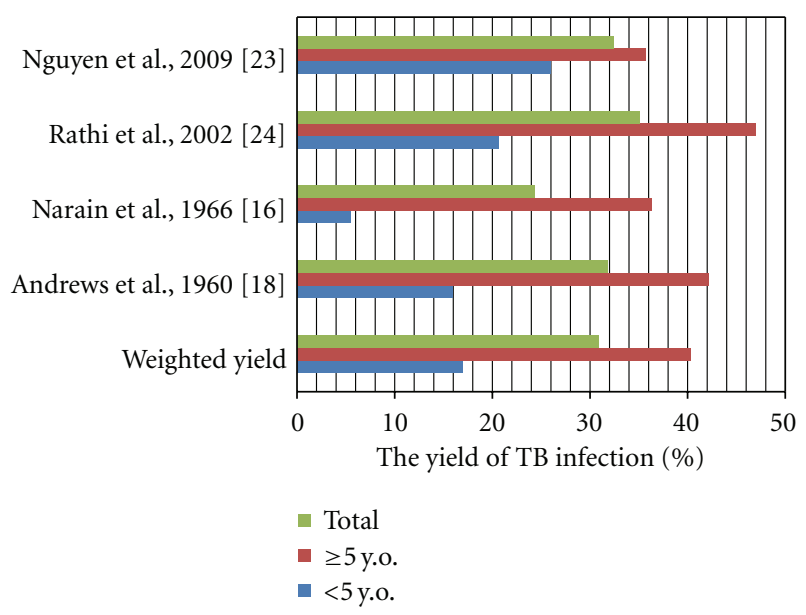

Figure 1: The yield of TB infection among children in household contacts.

\section{Discussion}

The prevalence of TB infection and disease among children living in the same house as a case of pulmonary TB in South East Asia varies between settings. This variation may be due to the different epidemiology features amongst the countries or to the heterogeneity among studies with regards to the characteristics of the index case and the criteria used for determining TB infection and disease. Nonetheless, TB infection among child contacts was common and would support recommendations for routine screening and management of child household contacts. The finding that TB disease is more prevalent among young children ( $<5$ years) is as expected given that young age is a well-established risk factor for disease following infection.

Various approaches and criteria were used to assess the outcome of contact investigation, indicating that there has not been a universal method accepted or implemented in South East Asia. For example, the study in The Philippines used a cut-off point of $5 \mathrm{~mm}$ induration to define positive TST, which is lower than the recommended $10 \mathrm{~mm}$ in a BCGvaccinated population [26]. The use of the cutoff may explain why this group reported the highest prevalence $(67.2 \%)$ of TB infection amongst the studies. For studies which defined a positive TST as $\geq 10 \mathrm{~mm}$ induration, the proportion of TB infection ranged from $24 \%$ to $48 \%[6,15,22,24,27-31]$. A meta-analysis of contact investigation in low- and middleincome countries by Morrison and colleagues revealed a prevalence of TB infection of $40 \%$ in children aged under 15 years [13].

Despite the evidence of high rates of infection and disease in child contacts in South East Asia, screening is rarely implemented. A cross-sectional study in India reported that only 31 of $220(14 \%)$ children younger than 14 years living in the same house as adults with pulmonary TB were screened for TB [32]. A higher yield of 52\% was reported by Tornee and co-workers in a prospective study in Thailand. [20]. The potential of contact screening upon identification of an infectious case in the community is emphasised by a recent study from South Africa which reported that most cases of young children with confirmed TB represented a missed prior opportunity for preventive therapy [33].

Isoniazid preventive therapy (IPT) which has proven efficacy in preventing TB disease in infected and uninfected child contacts is recommended for child contacts $<5$ years of age who have no evidence of TB disease $[8,34,35]$. Yet IPT is rarely provided. A study in India reported that, of 84 child contacts aged younger than 6 years, only 16 (19\%) were initiated on IPT [36]. In Malawi, of 365 child household contacts under five, only $33(9 \%)$ were actually screened for TB: $23(6 \%)$ received IPT, $6(2 \%)$ received antiTB treatment, and, in 4 (1\%), no action was taken [37]. When IPT is prescribed, poor adherence is another problem that is likely to reduce the effectiveness of this intervention [37]. Adherence rates of 15 to $28 \%$ have been reported from South Africa [38, 39].

A reason for the poor implementation of contact investigation and IPT provision in resource-limited countries is likely to be the lack of human resources. Health workers in TB endemic areas are overburdened by the identification and management of sputum smear-positive cases, which are the priority for treatment in any national TB programs. In addition, the awareness and knowledge of families and healthcare workers of the rationale and potential of IPT are lacking $[33,40]$. In Malawi, only $21 \%$ of TB patients who had child contacts aged 5 years or below were informed about the need for screening their children [37]. A more recent study in Malawi in 2006 reported that only $8 \%$ of sputum smear-positive cases brought their children to the clinic for screening despite provision of clear information [41].

Guidelines that are difficult to implement may also be a barrier for the implementation of contact investigation. As long as TST and CXR remain mandatory tests for screening, coverage in resource-limited settings cannot be expected to improve, and its impact on TB control is likely to be limited. TST and CXR are not readily available in primary health clinics in the region, where index cases are commonly identified and treated. These tests are usually performed at main hospitals located in cities, which increases transport and time costs. The use and interpretation of TST are also problematic: unaffordable for most families in resource-limited setting; require skill to perform, and a second hospital visit is necessary [10].

A more simple, cheap, feasible, efficient and patientfriendly method is required. The current WHO guideline [8] of symptom-based screening recommends symptom evaluation alone to decide whether the contact requires further investigation for TB disease or can be prescribed IPT directly. Asymptomatic child contacts aged less than 5 years can be provided IPT without further investigation. If $\mathrm{TB}$ is suspected at initial assessment or at subsequent followup, further investigation should be performed to establish or exclude a diagnosis of TB disease. Referral to a district or tertiary hospital may be necessary when there are uncertainties about the diagnosis. Therefore, TST or CXR is not necessarily performed in all child contacts [8].

A limitation of this systematic review is that it only includes published studies reported in English. More precise 
yields from contact investigation among child household contacts in the South East Asia would have been gained if unpublished studies and the grey literature such as reports from NTPs of each country were included.

\section{Conclusion}

Contact investigation studies in South East Asia indicate the potential of screening and IPT to reduce the risk of TB disease in child contacts, yet it is rarely implemented. Research is required to determine patient and health service barriers to screening to enable targeted effective intervention programs to be developed. One such research strategy could include a qualitative review of problems around the implementation of contact investigation and IPT provision for child contacts in the region. This will provide valuable information for the design of community-based interventions to improve the management of child contacts. A simple method of contact investigation standardised in the region is required.

\section{Acknowledgment}

The authors acknowledge Dr. Anna Ralph, a Senior Clinical Research Fellow at Menzies School of Health Research Darwin Australia, for her feedback on the content of the paper.

\section{References}

[1] World Health Organization, Tuberculosis Control in the South East Region. Annual Report, WHO, Geneva, Switzerland, 2009.

[2] World Health Organization, WHO Report 2010. Global Tuberculosis Control, WHO, Geneva, Switzerland, 2010.

[3] World Health Organization, Global Tuberculosis Control: A Short Update to the 2009 Report, WHO, Geneva, Switzerland, 2009.

[4] B. J. Marais, H. Ayles, S. M. Graham, and P. Godfrey-Faussett, "Screening and preventive therapy for tuberculosis," Clinics in Chest Medicine, vol. 30, no. 4, pp. 827-846, 2009.

[5] T. A. Kenyon, T. Creek, K. Laserson et al., "Risk factors for transmission of Mycobacterium tuberculosis from HIVinfected tuberculosis patients, Botswana," International Journal of Tuberculosis and Lung Disease, vol. 6, no. 10, pp. 843850, 2002.

[6] R. Sinfield, M. Nyirenda, S. Haves, E. M. Molyneux, and S. M. Graham, "Risk factors for TB infection and disease in young childhood contacts in Malawi," Annals of Tropical Paediatrics, vol. 26, no. 3, pp. 205-213, 2006.

[7] B. J. Marais, R. P. Gie, H. S. Schaaf et al., "The natural history of childhood intra-thoracic tuberculosis: a critical review of literature from the pre-chemotherapy era," International Journal of Tuberculosis and Lung Disease, vol. 8, no. 4, pp. 392402, 2004.

[8] World Health Organization, Guidance for National Tuberculosis Programmes on the Management of Tuberculosis in Children, WHO, Geneva, Switzerland, 2006.

[9] V. F. Gomes, A. Andersen, C. Wejse et al., "Impact of tuberculosis exposure at home on mortality in children under 5 years of age in Guinea-Bissau," Thorax, vol. 66, no. 2, pp. 163-167, 2011.
[10] R. Zachariah, M. P. Spielmann, A. D. Harries et al., "Passive versus active tuberculosis case finding and isoniazid preventive therapy among household contacts in a rural district of Malawi," International Journal of Tuberculosis and Lung Disease, vol. 7, no. 11, pp. 1033-1039, 2003.

[11] A. van Rie, N. Beyers, R. P. Gie, M. Kunneke, L. Zietsman, and P. R. Donald, "Childhood tuberculosis in an urban population in South Africa: burden and risk factor," Archives of Disease in Childhood, vol. 80, no. 5, pp. 433-437, 1999.

[12] A. G. Correa, "Unique aspects of tuberculosis in the pediatric population," Clinics in Chest Medicine, vol. 18, no. 1, pp. 8998, 1997.

[13] J. Morrison, M. Pai, and P. C. Hopewell, "Tuberculosis and latent tuberculosis infection in close contacts of people with pulmonary tuberculosis in low-income and middle-income countries: a systematic review and meta-analysis," The Lancet Infectious Diseases, vol. 8, no. 6, pp. 359-368, 2008.

[14] E. Liu, S. Cheng, X. Wang, D. Hu, T. Zhang, and C. Chu, "A systematic review of the investigation and management of close contacts of tuberculosis in China," Journal of Public Health, vol. 32, no. 4, pp. 461-466, 2010.

[15] M. Singh, M. L. Mynak, L. Kumar, J. L. Mathew, and S. K. Jindal, "Prevalence and risk factors for transmission of infection among children in household contact with adults having pulmonary tuberculosis," Archives of Disease in Childhood, vol. 90, no. 6, pp. 624-628, 2005.

[16] R. Narain, S. S. Nair, G. R. Rao, and P. Chandrasekhar, "Distribution of tuberculous infection and disease among households in a rural community," Bulletin of the World Health Organization, vol. 34, no. 4, pp. 639-654, 1966.

[17] R. Kumar, M. Saran, B. L. Verma, and R. N. Srivastava, "Pulmonary tuberculosis among contacts of patients with tuberculosis in an urban Indian population," Journal of Epidemiology and Community Health, vol. 38, no. 3, pp. 253258, 1984.

[18] R. H. Andrews, S. Devadatta, W. Fox, S. Radhakrishna, C. V. Ramakrishnan, and S. Velu, "Prevalence of tuberculosis among close family contacts of tuberculous patients in South India, and influence of segregation of the patient on early attack rate," Bulletin of the World Health Organization, vol. 23, pp. 463-510, 1960.

[19] S. Tornee, J. Kaewkungwal, W. Fungladda, U. Silachamroon, P. Akarasewi, and P. Sunakorn, "Risk factors for tuberculosis infection among household contacts in Bangkok, Thailand," Southeast Asian Journal of Tropical Medicine and Public Health, vol. 35, no. 2, pp. 375-383, 2004.

[20] S. Tornee, J. Kaewkungwal, W. Fungladda, U. Silachamroon, P. Akarasewi, and P. Sunakorn, "Factors associated with the household contact screening adherence of tuberculosis patients," Southeast Asian Journal of Tropical Medicine and Public Health, vol. 36, no. 2, pp. 331-340, 2005.

[21] K. Okada, T. E. Mao, T. Mori et al., "Performance of an interferon-gamma release assay for diagnosing latent tuberculosis infection in children," Epidemiology and Infection, vol. 136, no. 9, pp. 1179-1187, 2008.

[22] H. Iskandar, H. M. D. Nataprawira, H. Garna et al., "Tuberculosis prevalence among underfive children in household contact with negative acid fast bacili adult pulmonary tuberculosis," Paediatrica Indonesiana, vol. 48, no. 1, pp. 18-22, 2008.

[23] T. H. Nguyen, P. Odermatt, G. Slesak, and H. Barennes, "Risk of latent tuberculosis infection in children living in households with tuberculosis patients: a cross sectional survey in remote northern Lao People's Democratic Republic," BMC Infectious Diseases, vol. 9, article 96, 2009. 
[24] S. K. Rathi, S. Akhtar, M. H. Rahbar, and S. I. Azam, "Prevalence and risk factors associated with tuberculin skin test positivity among household contacts of smear-positive pulmonary tuberculosis cases in Umerkot, Pakistan," International Journal of Tuberculosis and Lung Disease, vol. 6, no. 10, pp. 851-857, 2002.

[25] R. M. L. Salazar-Vergara, I. G. Sia, T. E. Tupasi et al., “Tuberculosis infection and disease in children living in households of Filipino patients with tuberculosis: a preliminary report," International Journal of Tuberculosis and Lung Disease, vol. 7, no. 12, pp. S494-S500, 2003.

[26] M. Farhat, C. Greenaway, M. Pai, and D. Menzies, "Falsepositive tuberculin skin tests: what is the absolute effect of BCG and non-tuberculous mycobacteria?" International Journal of Tuberculosis and Lung Disease, vol. 10, no. 11, pp. 1192-1204, 2006.

[27] D. Guwatudde, M. Nakakeeto, E. C. Jones-Lopez et al., "Tuberculosis in household contacts of infectious cases in Kampala, Uganda," American Journal of Epidemiology, vol. 158, no. 9, pp. 887-898, 2003.

[28] X. Lin, V. Chongsuvivatwong, L. Lin, A. Geater, and R. Lijuan, "Dose-response relationship between treatment delay of smear-positive tuberculosis patients and intra-household transmission: a cross-sectional study," Transactions of the Royal Society of Tropical Medicine and Hygiene, vol. 102, no. 8, pp. 797-804, 2008.

[29] E. L. N. Maciel, L. W. H. Vieira, L. P. D. Molina, R. Alves, T. N. Prado, and R. Dietze, "Juvenile household contacts aged 15 or younger of patients with pulmonary TB in the greater metropolitan area of Vitória, Brazil: a cohort study," The Jornal Brasileiro de Pneumologia, vol. 35, no. 4, pp. 359-366, 2009.

[30] L. Teixeira, M. D. Perkins, J. L. Johnson et al., "Infection and disease among household contacts of patients with multidrugresistant tuberculosis," International Journal of Tuberculosis and Lung Disease, vol. 5, no. 4, pp. 321-328, 2001.

[31] L. M. D. Almeida, M. A. Barbieri, A. C. Da Paixão, and L. E. Cuevas, "Use of purified protein derivative to assess the risk of infection in children in close contact with adults with tuberculosis in a population with high Calmette-Guérin bacillus coverage," The Pediatric Infectious Disease Journal, vol. 20, no. 11, pp. 1061-1065, 2001.

[32] B. Rekha and S. Swaminathan, "Childhood tuberculosisglobal epidemiology and the impact of HIV," Paediatric Respiratory Reviews, vol. 8, no. 2, pp. 99-106, 2007.

[33] K. Du Preez, A. C. Hesseling, A. M. Mandalakas et al., "Opportunities for chemoprophylaxis in children with cultureconfirmed tuberculosis," Annals of Tropical Paediatrics: International Child Health, vol. 31, no. 4, pp. 301-310, 2011.

[34] M. J. Smieja, C. A. Marchetti, D. J. Cook, and F. M. Smaill, "Isoniazid for preventing tuberculosis in non-HIV infected persons," Cochrane Database of Systematic Reviews, no. 2, Article ID CD001363, 2000.

[35] K. H. K. Hsu, "Thirty years after isoniazid. Its impact on tuberculosis in children and adolescents," Journal of the American Medical Association, vol. 251, no. 10, pp. 1283-1285, 1984.

[36] V. V. Banu Rekha, K. Jagarajamma, F. Wares, V. Chandrasekaran, and S. Swaminathan, "Contact screening and chemoprophylaxis in India's Revised Tuberculosis Control Programme: a situational analysis," International Journal of Tuberculosis and Lung Disease, vol. 13, no. 12, pp. 1507-1512, 2009.

[37] N. J. M. Claessens, F. F. Gausi, S. Meijnen, M. M. Weismuller, F. M. Salaniponi, and A. D. Harries, "Screening childhood contacts of patients with smear-positive pulmonary tuberculosis in Malawi [Notes from the Field]," International Journal of Tuberculosis and Lung Disease, vol. 6, no. 4, pp. 362-364, 2002.

[38] B. J. Marais, S. van Zyl, H. S. Schaaf, M. van Aardt, R. P. Gie, and N. Beyers, "Adherence to isoniazid preventive chemotherapy: a prospective community based study," Archives of Disease in Childhood, vol. 91, no. 9, pp. 762-765, 2006.

[39] S. van Zyl, B. J. Marais, A. C. Hesseling, R. P. Gie, N. Beyers, and H. S. Schaaf, "Adherence to anti-tuberculosis chemoprophylaxis and treatment in children," International Journal of Tuberculosis and Lung Disease, vol. 10, no. 1, pp. 13$18,2006$.

[40] R. Lester, R. Hamilton, S. Charalambous et al., "Barriers to implementation of isoniazid preventive therapy in HIV clinics: a qualitative study," AIDS, vol. 24, no. 5, pp. S45-S48, 2010.

[41] M. Nyirenda, R. Sinfield, S. Haves, E. M. Molyneux, and S. M. Graham, "Poor attendance at a child TB contact clinic in Malawi [Notes from the Field]," International Journal of Tuberculosis and Lung Disease, vol. 10, no. 5, pp. 585-587, 2006. 


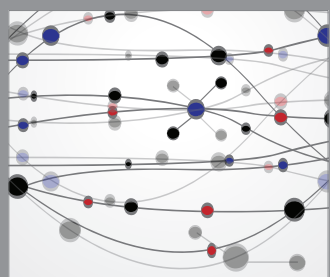

The Scientific World Journal
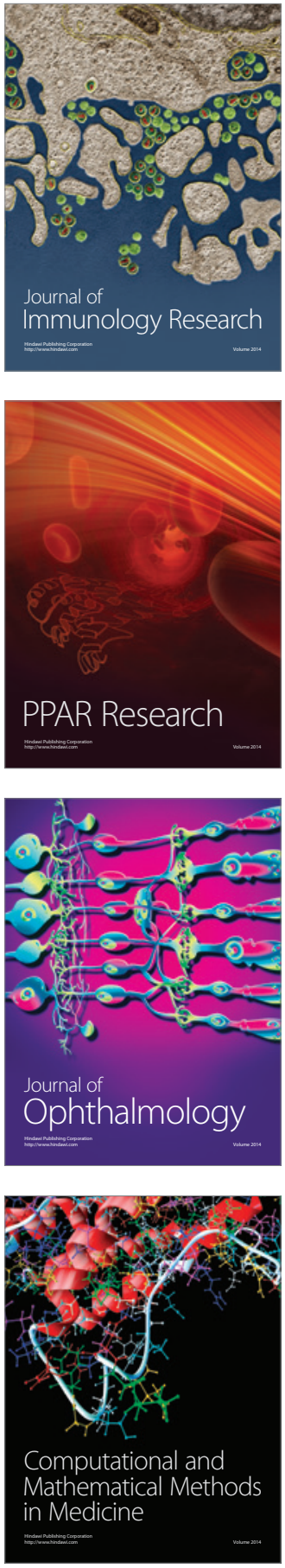

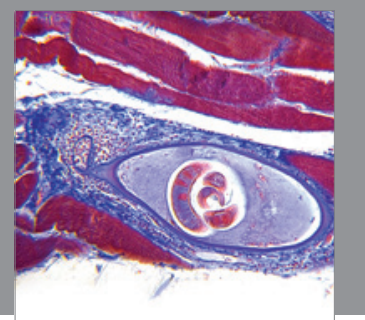

Gastroenterology

Research and Practice
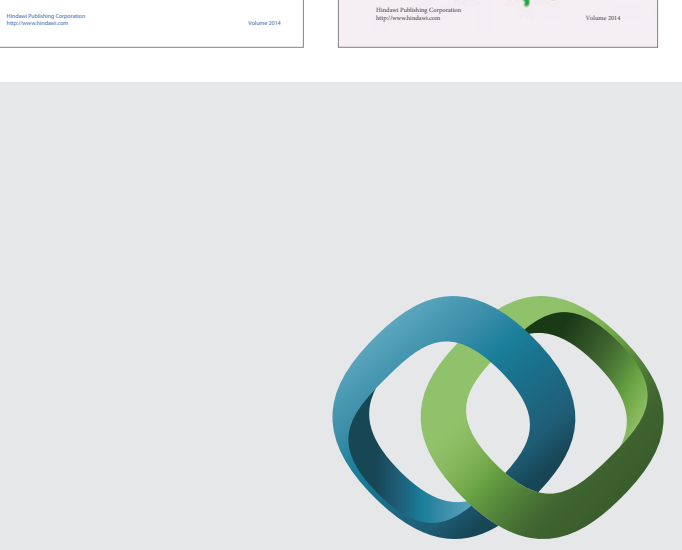

\section{Hindawi}

Submit your manuscripts at

http://www.hindawi.com
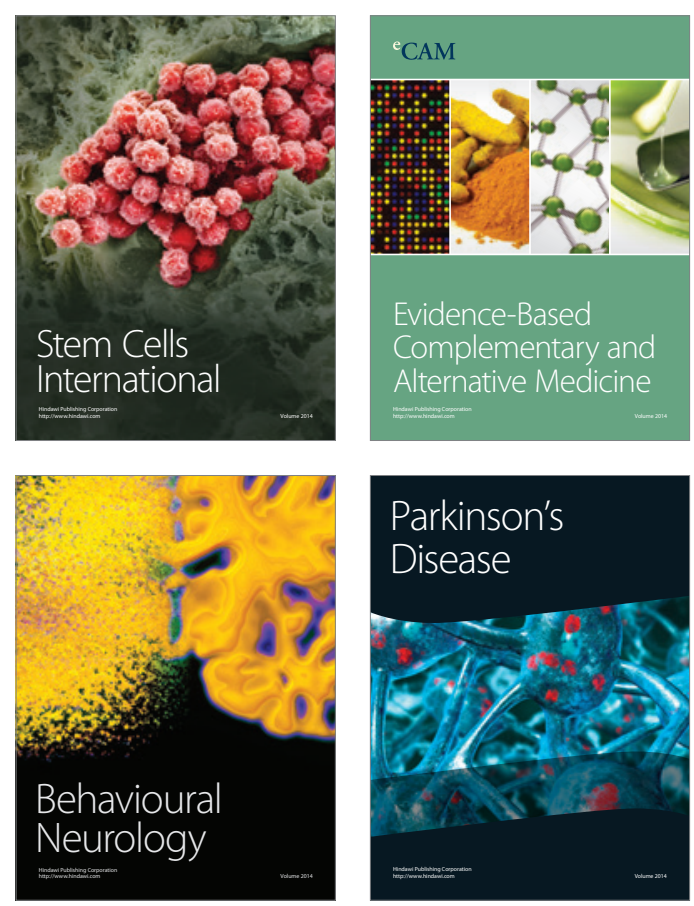

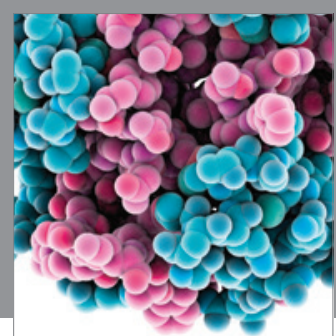

Journal of
Diabetes Research

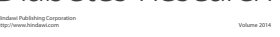

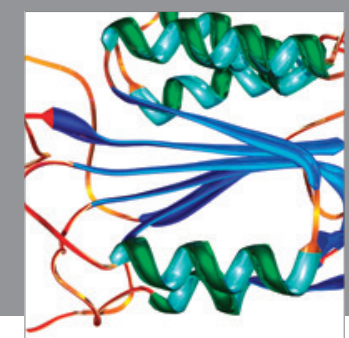

Disease Markers
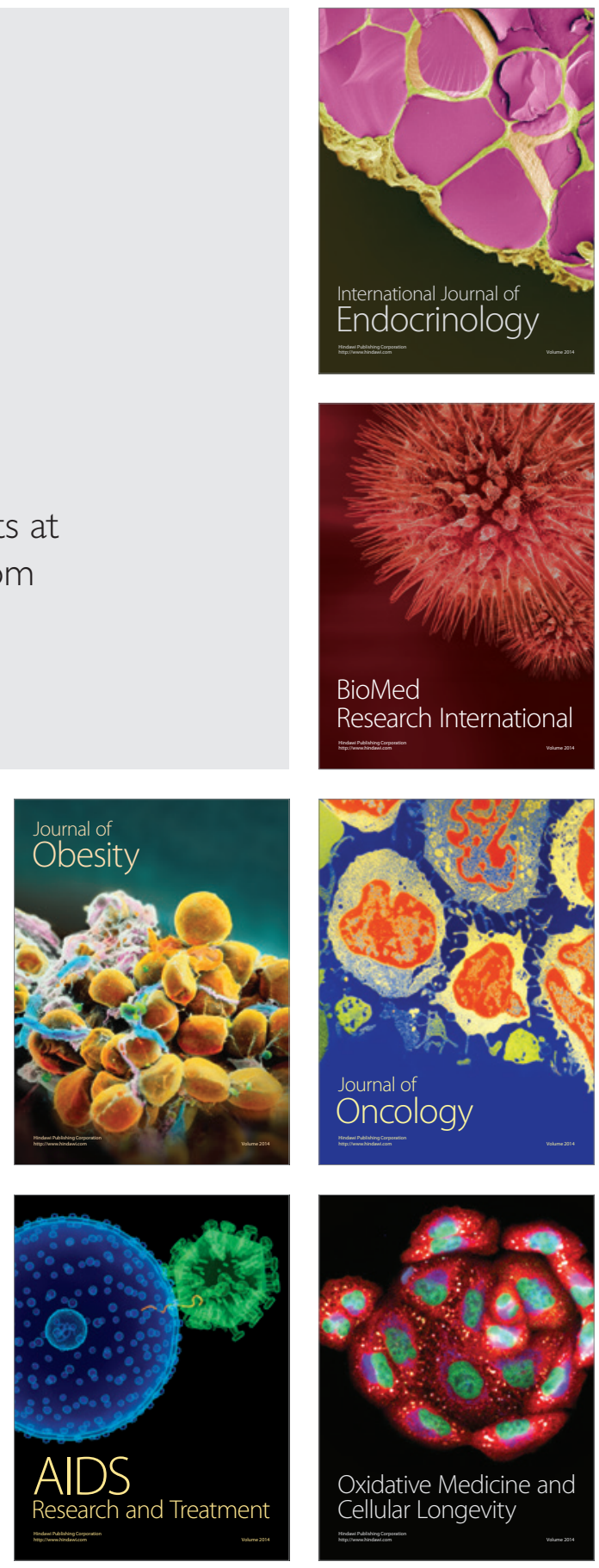